\title{
DESCOLORAÇÃO E DEGRADAÇÃO DO AZO CORANTE VERMELHO GRLX-220 POR OZONIZAÇÃo
}

Patrícia Kelly dos Santos, Karla Carvalho Fernandes e Luiz Antonio de Faria*

Instituto de Química, Universidade Federal de Uberlândia, Av. João Naves de Ávila, 2160, 38400-100 Uberlândia - MG, Brasil Admildo Costa de Freitas

Instituto Federal de Educação Ciência e Tecnologia do Triângulo Mineiro, Campus Uberaba, Rua João Batista Ribeiro, 4000, 38064-790 Uberaba - MG, Brasil

\section{Leonardo Morais da Silva}

Departamento de Química, Universidade Federal dos Vales do Jequitinhonha e Mucuri, Rod. MGT 367, km 583, 5000, 39100-000

Diamantina - MG, Brasil

Recebido em 24/9/10; aceito em 23/3/11; publicado na web em 10/6/11

\begin{abstract}
DISCOLORATION AND DEGRADATION OF THE RED GRLX-220 AZO-DYE BY OZONATION. The discoloration and degradation of the textile dye RED GRLX-220 using the electrochemically generated ozone was investigated. Total discoloration was rapidly achieved in both acid and basic conditions. A pseudo-first order kinetics was observed for discoloration, influenced by $\mathrm{pH}$ and ozonation time. A considerable degree of mineralization $(60 \%)$ was obtained after $30 \mathrm{~min}$ of ozonation in alkaline medium. The feasibility of organic matter oxidation during the ozonation process increased in both acidic and alkaline media. The toxicity decreased after the ozonation process, suggesting that the byproducts are less toxic than the parental compound.
\end{abstract}

Keywords: discoloration and degradation; ozone; semi-batch conditions.

\section{INTRODUÇÃO}

Em 2007, o Brasil importou 158,4 mil toneladas (correspondente a US\$ 515 milhões) e exportou, no mesmo período, 62 mil toneladas (equivalente a US\$ 145 milhões) de corantes e pigmentos. ${ }^{1}$ Diante dos números, pode-se avaliar a importância que este segmento representa para a economia do país. Entretanto, de dimensão igual ou superior é o impacto que este segmento representa para o meio ambiente. As indústrias de cosméticos, de couro, de papel, têxteis, entre outras, utilizam esta grande quantidade de corantes consumindo água limpa nos processos de produção, retornando ao ambiente como efluente. Especificamente, efluentes de indústrias têxteis são caracterizados por apresentar altas cargas de poluentes, originadas pelo descarte da solução residual dos banhos de tingimento. Estes, por sua vez, são constituídos principalmente por corantes, surfactantes, compostos orgânicos e inorgânicos, os quais são removidos após a lavagem do material que sofreu tingimento. ${ }^{2-11}$ Estima-se que cerca de $15 \%$ da produção mundial de corantes seja perdida para o meio ambiente durante a síntese, processamento ou aplicação desses corantes. ${ }^{12,13}$ A contaminação por esses compostos provoca efeitos danosos à biota, causando sérios problemas ambientais. ${ }^{14}$ Nesse sentido, a necessidade de encontrar tratamentos efetivos desses efluentes vem se tornando uma preocupação crescente, visando minimizar os problemas ambientais.

Métodos clássicos utilizados no tratamento de efluentes têxteis incluem diferentes combinações de processos biológicos (lodo ativado), físicos e químicos. ${ }^{15-17}$ Visto que as moléculas de corantes são complexas e estáveis, ${ }^{11}$ elas são difíceis de serem degradadas biologicamente e, portanto, não podem ser tratadas eficientemente pelo processo de lodo ativado ou pela combinação de métodos biológicos, químicos (coagulação) e físicos. ${ }^{11,18-20}$ Além disso, esses processos têm

*e-mail: lafaria@ufu.br o inconveniente de gerar uma grande quantidade de lodo ou efluente sólido, resultando num alto custo operacional para o tratamento e descarte destes materiais. ${ }^{21,22}$ Devido a isso, e também por razões ecológicas, dentre os tratamentos químicos que vêm sendo desenvolvidos tem sido mostrado que os processos de oxidação avançados (POA's) representam alternativas para redução de subprodutos e cor desses efluentes..$^{2-10,20,22-24}$ Estes processos são baseados na geração do radical hidroxila $\mathrm{OH}^{\bullet}$ altamente reativo com potencial de oxidação de 2,80 V (vs. ERH), capazes de degradar substâncias orgânicas presentes em efluentes industriais. ${ }^{24}$ Os POA's também têm sido utilizados em combinação com os métodos clássicos de modo a fornecer uma eficiente remoção de cor, demanda química de oxigênio (DQO) e carbono orgânico total (COT) dos efluentes têxteis. ${ }^{18,22}$

Dentre os diversos POA's existentes, a ozonização é um importante processo coadjuvante para o tratamento de diferentes efluentes contendo uma alta carga de compostos recalcitrantes. ${ }^{25-30}$ De modo geral, a eficiência de um POA depende das características químicas do efluente a ser tratado, tais como, $\mathrm{pH}$, turbidez, COT-DQO e da presença de radicais aceptores..$^{20}$ No caso específico da ozonização, a eficiência depende do COT do efluente. ${ }^{18}$ Para efluentes com resíduos de corantes de baixa resistência à degradação, a ozonização sozinha é suficiente para eliminar totalmente a cor e reduzir a turbidez. Entretanto, para efluentes com resíduos de corantes de média e alta resistência à degradação, a ozonização tem se mostrado adequada para reduzir a cor, mas não suficiente para reduzir a turbidez. Nesses casos, foi relatado ser necessário utilizar a coagulação com sulfato de alumínio $\left(\sim 60 \mathrm{mg} \mathrm{dm}^{-3}\right)$ ou com polímeros especialmente designados para este fim..$^{31,32}$ Tzitzi et al ${ }^{32}$ reportaram que a ozonização do efluente após a aplicação do processo coagulação-precipitação promoveu uma descoloração mais eficiente (>90\%) e redução de $\operatorname{DQO}(>30 \%)$, enquanto a biodegradabilidade aumentou, permitindo uma degradação efetiva pelo processo com lodo ativado. ${ }^{18,20,22}$ Deste modo, a combinação da ozonização com outros processos de tratamentos integrados (físicos, 
químicos ou biológicos) tem mostrado ser uma tecnologia altamente promissora para tratar efluentes de industrias têxteis, além de reduzir o descarte de lodo. ${ }^{18,25,26}$

O custo da produção de ozônio diminuiu quase $50 \%$ nas últimas duas décadas e, portanto, um grande número de novas aplicações industriais tem surgido recentemente. ${ }^{18,20}$ Devido ao ozônio ser instável e não poder ser armazenado por um longo período, ele tem sido gerado no local da aplicação. ${ }^{27,28,30}$ Ozônio pode ser gerado in situ usando-se as seguintes tecnologias: ${ }^{27,32}$ fotoquímica (radiação UV); corona (descarga elétrica silenciosa) e eletroquímica (eletrólise de uma solução aquosa ou água pura). A tecnologia mais comum é a corona, onde um gás seco, ar ou oxigênio puro, é submetido a uma descarga elétrica silenciosa. ${ }^{20,27,33}$ A tecnologia eletroquímica tem mostrado ser uma alternativa promissora para geração in situ de ozônio, ${ }^{20,23,27,28,30}$ apresentando algumas características que não são conseguidas com o processo corona, tornando-se uma alternativa interessante para várias aplicações do ozônio. ${ }^{20,28}$

Ozonizadores eletrolíticos baseados na tecnologia do eletrólito polimérico sólido, os quais operam na ausência de eletrólitos líquidos convencionais e em temperatura ambiente $\left(\sim 30{ }^{\circ} \mathrm{C}\right)$, permitem que o ozônio seja aplicado diretamente na água que flui pelo reator, tornando possível várias aplicações envolvendo processos de combustão de poluentes e/ou de desinfecção. ${ }^{20,34}$ Neste caso, a demanda de energia total é minimizada, visto que a produção de $\mathrm{O}_{3}$ é efetuada em temperatura ambiente (não é necessário gasto com refrigeração) enquanto que a alta velocidade de transferência de massa do ozônio da fase gasosa para a fase aquosa evita o uso de acessórios, tais como, difusores de gás e sistemas de bombeamento. ${ }^{20}$

Outra tecnologia eletroquímica de produção de ozônio (PEO) é baseada no uso de eletrólitos especialmente designados para a produção de ozônio, ${ }^{35,36}$ tendo a vantagem de ter a redução de oxigênio como processo catódico. Como resultado, a demanda específica de energia torna-se muito próxima àquela do dispositivo convencional corona. ${ }^{35}$ Esta tecnologia fornece uma eficiência muito alta $(\geq 35$ $\% \mathrm{p} / \mathrm{p}$ ), tornando este ozonizador eletroquímico competitivo com a tecnologia corona para aplicações onde seja necessária uma alta concentração de $\mathrm{O}_{3}$ na fase gasosa.

O objetivo deste trabalho foi investigar a aplicação do ozônio gerado eletroquimicamente na descoloração e degradação, em condições ácida e básica, do corante têxtil Vermelho GRLX-220.

\section{PARTE EXPERIMENTAL}

\section{Produção eletroquímica de ozônio}

A geração eletroquímica de ozônio e as correspondentes reações de ozonização de soluções aquosas contendo o corante têxtil Vermelho GRLX-220 foram efetuadas utilizando-se o conjunto experimental apresentado na Figura 1. O reator eletroquímico de produção de ozônio, construído no laboratório para estes experimentos, o qual foi primeiramente desenvolvido por Da Silva et al. ${ }^{23}$ apresenta uma eficiência de corrente para a produção eletroquímica de ozônio (PEO) de até $21 \% \mathrm{p} / \mathrm{p} \%$ (taxa de geração de $\mathrm{O}_{3}$ de $\sim 5 \mathrm{~g} \mathrm{~h}^{-1}$ e um consumo específico de energia elétrica de $\left.70 \mathrm{Whg}^{-1}\right)$. A mistura gasosa $\left(\mathrm{O}_{2} / \mathrm{O}_{3}\right)$ proveniente do compartimento anódico é separada do eletrólito circulante usando-se um frasco separador de gases, sendo posteriormente introduzida no reator de coluna tipo bolha (frasco reacional onde ocorre a ozonização). O ozônio é gerado no compartimento anódico, o qual é constituído do ânodo Ti/ $/ \mathrm{PbO}_{2}$, enquanto o cátodo é constituído de aço 316, sendo separados por uma membrana trocadora de prótons Nafion $117 .{ }^{23}$ A corrente elétrica aplicada ao reator eletroquímico e a temperatura do eletrólito foram ajustadas para fornecer uma taxa de geração de ozônio constante de $\sim 0,48 \mathrm{~g} \mathrm{~h}^{-1}$. O reator eletroquímico

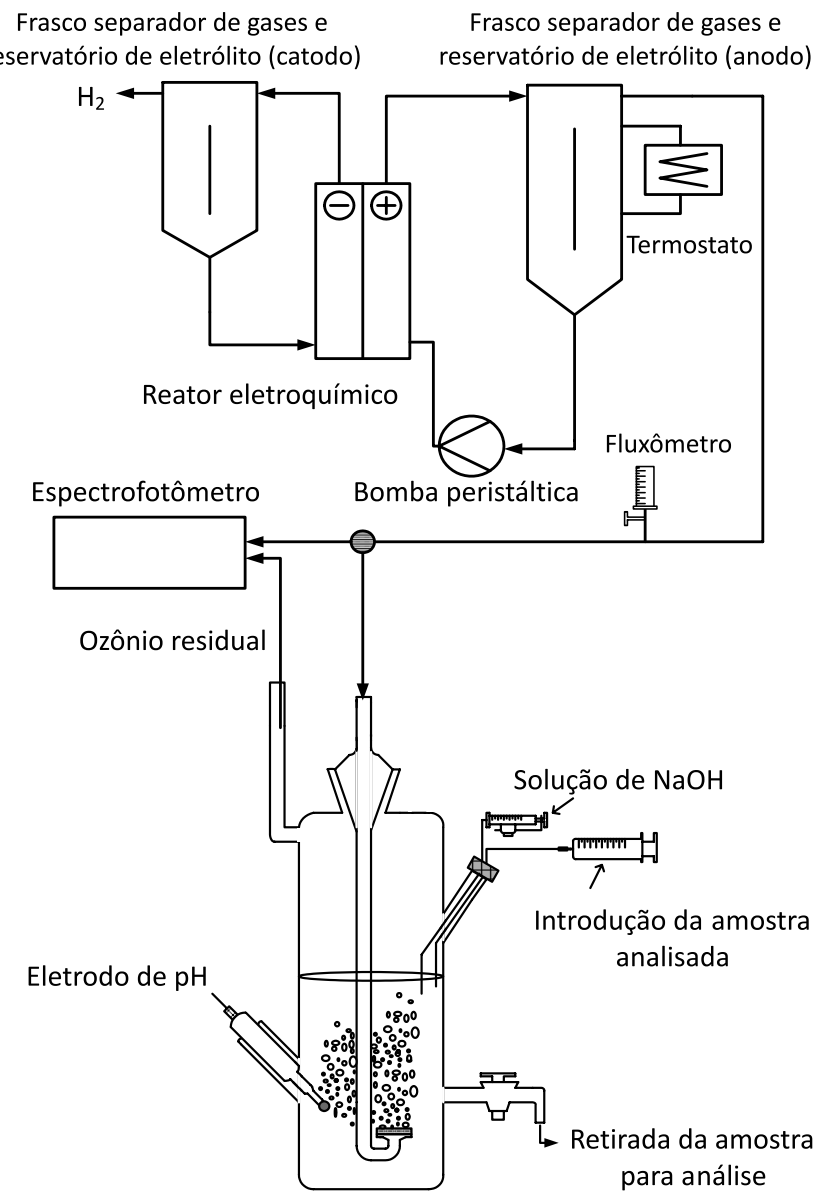

Figura 1. Diagrama do conjunto experimental utilizado na geração eletroquímica de ozônio e na ozonização, sob condições de semibatelada, de soluções aquosas contendo o corante Vermelho GRLX-220

foi alimentado por uma fonte de corrente contínua de $80 \mathrm{~A} / 12 \mathrm{~V}$. Em todos os experimentos o eletrólito $\left(3,0 \mathrm{~mol} \mathrm{dm}^{-3} \mathrm{H}_{2} \mathrm{SO}_{4}+0,03 \mathrm{~mol}\right.$ $\mathrm{dm}^{-3} \mathrm{KPF}_{6}$ ) foi circulado no compartimento anódico utilizando uma vazão $\left(\mathrm{G}_{\mathrm{E}}\right)$ de $60 \mathrm{dm}^{3} \mathrm{~h}^{-1}$, empregando-se uma bomba peristáltica da Cole-Parmer modelo 7018-21 Masterflex.

A velocidade linear do eletrólito foi de $1,30 \mathrm{~cm} \mathrm{~s}^{-1} \mathrm{e}$ a velocidade espacial de $5,19 \mathrm{~min}^{-1}$. O fluxo foi do tipo turbulento ( $\left.\operatorname{Re}>3000\right)$. $\mathrm{O}$ controle de temperatura do eletrólito $\left(0{ }^{\circ} \mathrm{C}\right)$ foi realizado através de um banho ultratermostatizado da Nova Ética modelo 521-3D, o qual foi conectado ao reservatório do eletrólito (todo de vidro)/frasco separador de gás. A temperatura do eletrólito na superfície do ânodo $\left(0{ }^{\circ} \mathrm{C}\right)$ foi monitorada com um termopar digital da Fluke modelo 61.

A concentração do ozônio na fase gasosa foi analisada por medidas de absorção UV em $254 \mathrm{~nm}$, utilizando-se uma célula de fluxo gasosa de quartzo, fabricada no próprio laboratório. A absorbância foi lida em condições estacionárias após 15 min de polarização da célula. A reprodutibilidade da determinação de ozônio foi de 2,0-2,5\% e a sensibilidade de $0,0396 \mathrm{dm}^{3} \mathrm{mg}^{-1}$. Não foi observada interferência no comprimento de onda de $254 \mathrm{~nm}$.

A taxa de geração de $\mathrm{O}_{3}, v_{\text {PEO }}$, foi calculada através da Equação 1:23

$$
v_{P E O}\left(g h^{-1}\right)=\frac{3600\left(A G_{A} M\right)}{\varepsilon . l}
$$

onde $\mathrm{A}=$ absorbância em $254 \mathrm{~nm} ; \mathrm{G}_{\mathrm{A}}=$ vazão gasosa $\left(\mathrm{O}_{2} / \mathrm{O}_{3}\right)\left(\mathrm{dm}^{3}\right.$ $\left.\mathrm{s}^{-1}\right) ; \varepsilon=3024 \mathrm{dm}^{3} \mathrm{~mol}^{-1} \mathrm{~cm}^{-1}$ é a absortividade do ozônio em $254 \mathrm{~nm}$ 
na fase gasosa; $l=$ percurso ótico $(0,63 \mathrm{~cm})$ e $M=$ massa molar do ozônio $\left(48 \mathrm{~g} \mathrm{~mol}^{-1}\right)$.

\section{Ozonização das soluções do corante têxtil vermelho GRLX-220}

Soluções do corante têxtil Vermelho GRLX-200, fornecido por uma indústria têxtil de Divinópolis/MG, foram preparadas pela dissolução do corante em água destilada. A estrutura molecular do corante Vermelho GRLX-220 é mostrada na Figura 2.

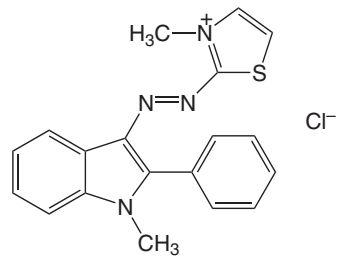

Figura 2. Fórmula estrutural do corante Vermelho GRLX-220. Fórmula molecular: $\mathrm{C}_{19} \mathrm{H}_{17} \mathrm{~N}_{4} \mathrm{SCl}$. Nomenclatura oficial: 3-metil-2-((-1-metil-2-fenil1H-indol-3yl) azo) thiazolium

Segundo informações contidas na ficha do produto, a solubilidade do corante em água é de $60-70 \mathrm{~g} \mathrm{dm}^{-3}$, a $80{ }^{\circ} \mathrm{C}$, enquanto uma solução contendo $10 \mathrm{~g} \mathrm{dm}^{-3}$ do corante apresenta, a $20{ }^{\circ} \mathrm{C}$, um $\mathrm{pH}$ na faixa de 2,0-3,0.

\section{Cinética de descoloração}

A remoção de cor foi estudada em condições de semibatelada $\left(\mathrm{V}=0,8 \mathrm{dm}^{3}\right.$ ) usando um reator de coluna tipo bolha (Figura 1). A mistura gasosa $\left(\mathrm{O}_{2} / \mathrm{O}_{3}\right)$, produzida no reator eletroquímico, foi borbulhada através de um difusor de placa porosa (Schott\#2, porosidade grossa; $\mathrm{A}=3,5 \mathrm{~cm}^{2}$ ) disposto na base do reator de coluna de bolha. A concentração de ozônio na fase aquosa foi calculada em $254 \mathrm{~nm}$ $\left(\varepsilon=2900 \mathrm{dm}^{3} \mathrm{~mol}^{-1} \mathrm{~cm}^{-1}\right)^{33}$ em função do tempo de ozonização até a condição de saturação ser alcançada.

$\mathrm{O}$ estudo cinético da remoção de cor foi efetuado medindo-se a absorbância no comprimento de onda inicialmente localizado em $530 \mathrm{~nm}\left(\lambda_{\text {máx }}\right)$, tanto em solução alcalina com em ácida, durante os primeiros 65 min de reação, utilizando-se um espectrofotômetro de varredura da Mecasys modelo Optizen 2120UV Plus. A ozonização foi efetuada em soluções alcalina ( $\mathrm{pH}$ ajustado para 12 pela adição de $\mathrm{NaOH}$ ) e ácida ( $\mathrm{pH} 4$, da solução natural). Todas as amostras, apresentando uma concentração inicial de corante, $[\mathrm{C}]_{0}$, de $200 \mathrm{mg}$ $\mathrm{dm}^{-3}$, foram continuamente ozonizadas durante $65 \mathrm{~min}$. $\mathrm{O} \mathrm{pH}$ foi monitorado utilizando-se um eletrodo de vidro combinado (Ag/ $\mathrm{AgCl}, \mathrm{Cl}^{-}$) (Figura 1).

\section{Taxa de degradação}

O carbono orgânico total (COT) foi determinado utilizando-se um analisador de COT da Shimadzu modelo 5000A. Medidas da demanda química de oxigênio (DQO) foram efetuadas seguindo o procedimento padrão. ${ }^{37} \mathrm{~A}$ degradação das soluções do corante $(0,8$ $\mathrm{dm}^{3}$ e $[\mathrm{C}]_{0}=200 \mathrm{mg} \mathrm{dm}^{-3}$ ) foi investigada, sem ajuste periódico do $\mathrm{pH}$, interrompendo-se o processo de ozonização para retirada das alíquotas, até completar o intervalo de tratamento com ozônio de 1,0 h. Um total de 18 amostras foram retiradas para avaliar a eficiência da degradação (medidas de DQO e COT).

\section{Avaliação da toxicidade}

O procedimento da avaliação da toxicidade foi efetuado utilizan- do-se a metodologia de Meyer adaptada. ${ }^{38}$ Em cada determinação foram utilizadas 10 larvas de Artemia salina que, após eclodidas, foram transferidas para tubos contendo água artificial do mar (chamadas de controle) e amostras dos efluentes sintéticos, antes e após a etapa de ozonização. Os testes foram feitos em triplicata, a contagem dos animais vivos e mortos foi realizada após 24 e $48 \mathrm{~h}$. A porcentagem de mortalidade foi corrigida utilizando a fórmula de Abbot, ${ }^{39}$ que fornece a porcentagem de mortalidade levando-se em consideração o número de mortes do controle:

$$
\% \text { mortalidade }=100 \times \frac{(\% \mathrm{~T}-\% \mathrm{C})}{(100 \%-\% \mathrm{C})}
$$

onde: \% T representa a mortalidade das Artemias testadas com o efluente de interesse e \% C, a mortalidade das Artemias utilizadas como controle. O controle consiste de 10 larvas de Artemias na água marinha artificial sem o efluente sintético. Todas as amostras foram submetidas às devidas correções da salinidade, a fim de evitar que as larvas sofressem o fenômeno da osmose.

\section{RESULTADOS E DISCUSSÃO}

\section{Acompanhamento espectrofotométrico da degradação do corante Vermelho GRLX-220 em meios ácido e básico}

Foram registrados vários espectros de absorção na região UVVis de soluções aquosas do corante comercial Vermelho GRLX-220. O espectro é caracterizado por um pico intenso em $530 \mathrm{~nm}$ (o que concorda com a ficha do produto) e outros de menores intensidades, cabendo destacar o pico localizado ao redor de $300 \mathrm{~nm}$, frequentemente presentes em outros corantes e atribuídos às insaturações e anéis aromáticos. O pico em $530 \mathrm{~nm}$ corresponde à absorção do grupo azo $(-\mathrm{N}=\mathrm{N}-)$, responsável pela cor vermelha do corante. Foi construída uma curva de calibração e os resultados, tanto em meio ácido como básico, foram excelentes, apresentando coeficientes de correlação de 0,9998 para ambos pH's.

A descoloração das soluções contendo o corante vermelho GRLX-220 foi efetuada em função do tempo de ozonização, em diferentes valores iniciais de $\mathrm{pH}$ (4 ou 12). A Figura 3 mostra a evolução dos espectros de absorção (em meio ácido) durante a ozonização, sendo representativa para os meios ácido e básico.

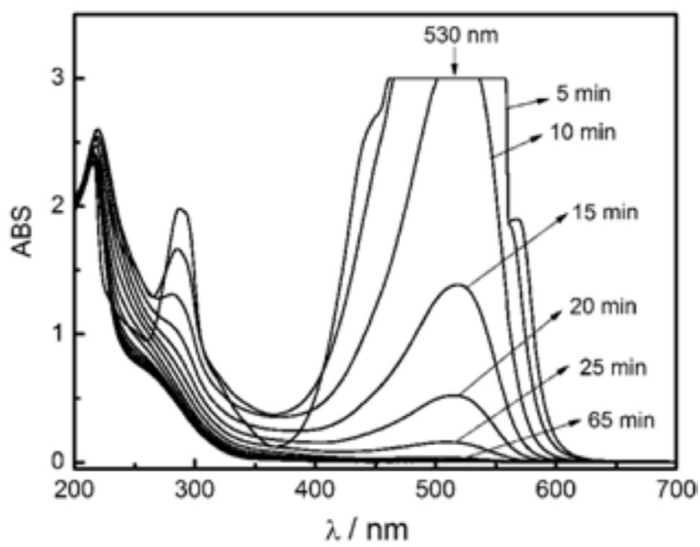

Figura 3. Influência do tempo de ozonização sobre o espectro de absorção do corante em meio ácido ( $\mathrm{pH} 4) . v_{P E O}=0,48 \mathrm{~g} \mathrm{~h}^{-1} \cdot[\mathrm{C}]_{o}=200 \mathrm{mg} \mathrm{dm}^{-3}$

Os primeiros pontos, obtidos com uma concentração inicial do corante de $200 \mathrm{mg} \mathrm{dm}^{-3}$, correspondentes ao intervalo de 0 a $10 \mathrm{~min}$ de 
ozonização, excedem a escala do aparelho. Após 15 min de ozonização, a concentração diminuiu de 200 para $25 \mathrm{mg} \mathrm{dm}^{-3}$ (redução de 87,5\%), significando que ocorreu uma remoção significativa de cor em tempos curtos de ozonização. Uma análise criteriosa da Figura 3 permite verificar ainda que ocorre um ligeiro deslocamento do $\lambda_{\text {máx }}$ para valores inferiores a $530 \mathrm{~nm}$ com o avanço do experimento de ozonização.

O fato de haver uma forte redução nos valores da absorbância, medida no $\lambda_{\text {máx }}$, com o tempo de ozonização, indica que o centro cromóforo presente na molécula do corante sofre um intenso ataque eletrofílico pelos agentes oxidantes $\mathrm{O}_{3}$ (meio ácido) e $\mathrm{OH}^{\bullet}$ (meio básico) Esta conclusão está de acordo com a literatura ${ }^{40}$ onde é proposto que o centro cromóforo, por possuir elevada densidade eletrônica nas ligações azo, é facilmente atacado por espécies eletrofílicas fortes presentes na fase aquosa. Esta ruptura, como consequência, promove o surgimento de novas espécies secundárias podendo ocasionar um ligeiro deslocamento do $\lambda_{\text {máx }}$

A Figura 4 exibe o efeito do $\mathrm{pH}$ sobre a descoloração das soluções dos corantes.

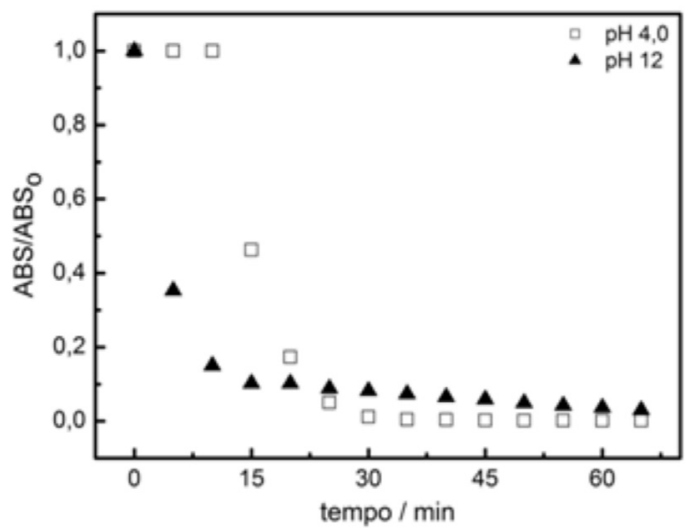

Figura 4. Dependência da absorbância $\left(\lambda_{\max }=530 \mathrm{~nm}\right)$ com o tempo de ozonização. $[C]_{o}=200 \mathrm{mg} \mathrm{dm}^{-3}$. (口) $\mathrm{pH} \mathrm{4;} \mathrm{( \Delta )} \mathrm{pH} 12$

A princípio, comparando-se o comportamento dos resultados da Figura 4 nos diferentes $\mathrm{pH}$ 's, pode-se supor que a velocidade de degradação, nos instantes iniciais, é superior em meio básico, mas não é o que ocorre. A elevada redução da absorção em meio básico (0 a 15 min) também ocorre mesmo sem a aplicação de ozônio, isto é, há uma diminuição da absorção no $\lambda_{\text {máx }}$ do corante mesmo sem tê-lo submetido à reação de ozonólise. Como a solução inicial do corante é ácida (pH 4), este fenômeno é consequência da reação corante (ácido) + base $\rightarrow$ sal $+\mathrm{H}_{2} \mathrm{O}$. Portanto, ao se iniciar a reação de ozonólise, em meio básico, grande quantidade de corante já reagiu (observa-se a ligeira formação de precipitado) e, por isso, a absorção inicial é muito inferior à verificada em meio ácido. Exatamente para poder observar esse fenômeno optou-se por trabalhar com concentrações iniciais elevadas ( $200 \mathrm{mg}$ $\mathrm{dm}^{-3}$ ) com soluções recém-preparadas em ambos pH's.

Pode-se verificar na Figura 4 que após 25 min de ozonização a situação se inverteu, com a descoloração passando a ser ligeiramente superior em meio ácido. Isto pode ser devido ao fato de que, com o transcorrer da ozonização, também vai aumentando a quantidade de sal formado, sendo este mais resistente à oxidação pelo $\mathrm{O}_{3}$ e/ou radicais $\mathrm{OH}^{\circ}$, além de sua remoção da fase aquosa como corpo de fundo. Por isso, a velocidade de descoloração em meio ácido ultrapassa a verificada em meio básico após 25 min de ozonização. Está em andamento um estudo cinético da formação do sal em meio básico e das degradações efetuadas em função do intervalo de tempo a partir do qual as soluções acabaram de ser preparadas.

Após 65 min de ozonização, a redução de cor totalizou 99,9\% em meio ácido, enquanto em meio básico foi de 97,5\%. Esses resultados estão de acordo com vários estudos reportados na literatura, ${ }^{20,23.40}$ confirmando que a ozonização é um processo muito eficiente para a remoção de cor. Correspondentemente com a literatura, ${ }^{20,23}$ a descoloração via ozonização é rápida em ambas condições de $\mathrm{pH}(t \leq 20$ min). Este comportamento pode ser atribuído à natureza eletrofílica do agente oxidante ${ }^{10,11,40}$ presente tanto no processo de ozonização direto (ataque por moléculas de $\mathrm{O}_{3}$, Equação 3) como no indireto (ataque via radicais $\mathrm{OH}^{\bullet}$ (Equações 4 e 5)):

$$
\begin{gathered}
\mathrm{O}_{3}(\mathrm{aq})+\text { orgânicos } \rightarrow \mathrm{R}^{\bullet} \rightarrow \text { produtos da oxidação } \\
\mathrm{O}_{3}(\mathrm{aq})+\mathrm{OH}^{-} \rightarrow \mathrm{OH}^{\bullet} \\
\mathrm{OH}^{\bullet}+\text { orgânicos } \rightarrow \text { produtos da oxidação }
\end{gathered}
$$

\section{Comportamento cinético da descoloração em fluxo constante de ozônio}

A ozonização de compostos orgânicos depende do $\mathrm{pH}$, da reação química (cinética intrínseca), transferência de massa do ozônio e carga de ozônio na fase aquosa. ${ }^{20,28,41,42}$ Como discutido por Wu e Wang, ${ }^{37}$ a força motriz para a transferência de massa do ozônio, compreendendo a diferença entre a concentração de ozônio dissolvido e em equilíbrio na interface gás/liquido, é dependente do sistema.

A dependência desta força motriz para a transferência de massa com as características do efluente resulta do fato de que a concentração de ozônio dissolvido varia consideravelmente com a velocidade da própria degradação do $\mathrm{O}_{3}$ e com a natureza da reação química. Como discutido por Franco et al., ${ }^{20}$ existe uma diferença entre a descoloração total da solução do corante e a degradação total (mineralização) das moléculas do corante. De fato, o processo de descoloração via ozonização ocorre quando as ligações cromóforas são removidas, enquanto muitos subprodutos da molécula parental do corante podem permanecer estáveis em solução. ${ }^{11,20}$ Portanto, a descoloração pode ser a etapa inicial na rota de degradação da molécula do corante, a qual não é necessariamente acompanhada pela quantidade de carbono orgânico removido (grau considerável de mineralização). ${ }^{20,23,43}$ Do ponto de vista prático, a descoloração via ozonização requer uma carga de oxidante menor que a mineralização, tornando-se assim uma interessante etapa de pré-tratamento para o processo bioquímico tradicional, o qual frequentemente apresenta uma pobre eficiência para a remoção de cor . ${ }^{11,28}$

Os dados de descoloração experimental revelam um decaimento exponencial das medidas de absorbância num comprimento de onda fixo $(530 \mathrm{~nm}$ ) em função do tempo de ozonização (Figura 4). Um comportamento linear muito bom $(r>0,998)$ foi verificado usando um modelo cinético de pseudoprimeira ordem (Figura 5). Um es-

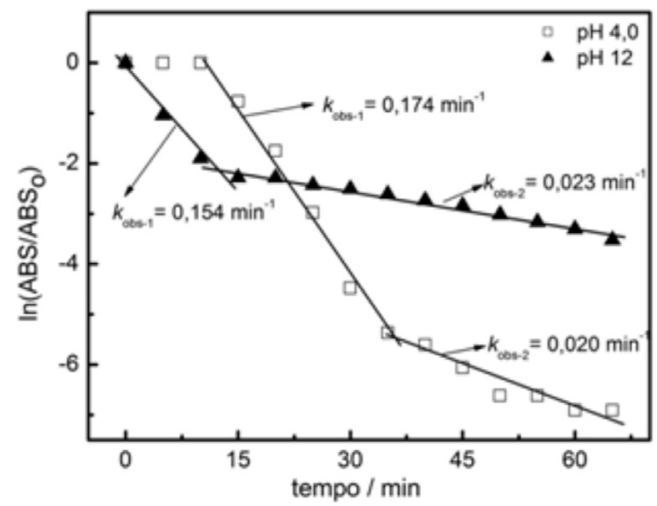

Figura 5. Perfis cinéticos de pseudoprimeira ordem obtidos para a descoloração do corante comercial Vermelho GRLX-220 em função do pH inicial da solução. $[C]_{o}=200 \mathrm{mg} \mathrm{dm}^{-3}$ 
tudo recente realizado por Peng e Fan, ${ }^{44}$ sobre a ordem cinética da descoloração de corante via ozonização sobre condições de mistura perfeita, reportou que as condições de pseudoprimeira ordem são na realidade obtidas somente quando a razão molar ozônio/corante permanece no intervalo de 5,57 a 9,31. De acordo com esse estudo, a ordem de reação pode não ser constante durante todo o processo de ozonização, visto que ela pode mudar com a variação da razão ozônio/ corante durante o progresso do processo de ozonização.

Durante o curso da reação de ozonização é possível que as moléculas dos subprodutos compitam com as moléculas do corante de partida pelo oxidante (ozônio e/ou radical hidroxila). ${ }^{20}$ Neste caso, a ordem de reação para o processo de descoloração $(n)$ pode ser determinada usando-se o ajuste da regressão dos mínimos quadrados da forma integrada da expressão do balanço de massa: ${ }^{20,45}$

$$
\frac{d[c r o]}{d t}=k_{o b s}[c r o]^{n}
$$

Considerando que o processo de descoloração segue um modelo de pseudoprimeira ordem $(n=1)$, a integração da Equação 6 fornece a seguinte relação:

$$
\ln \frac{[c r o]}{[c r o]_{0}}=-k_{\text {obs }} t
$$

onde [cro] e [cro $]_{0}$ são as concentrações cromóforas instantânea e inicial, respectivamente. ${ }^{20}$

Devido à natureza complexa do processo de ozonização de moléculas orgânicas de cadeias longas, ${ }^{46}$ a constante de velocidade global de pseudoprimeira ordem, $k_{\mathrm{obs}}$, contém o efeito da cinética intrínseca e pode refletir mais que um regime de massa/transferência química, ${ }^{20,45,46}$ algumas vezes resultando numa expressão mais complexa para $k_{\mathrm{obs}}: 45$

$$
k_{o b s}=\alpha\left(v_{P E O}\right)^{X}\left(\left[H O^{-}\right]^{Y}\left([c r o]_{0}\left[H O^{\bullet}\right]\right)^{Z}\right.
$$

onde $v_{\mathrm{PEO}}=$ velocidade de aplicação de ozônio; $\left[\mathrm{OH}^{\bullet}\right]=$ concentração do radical hidroxila e $\left[\mathrm{OH}^{-}\right]=$concentração do ânion hidroxila. $\alpha$, $\mathrm{x}, \mathrm{y}$ e $\mathrm{z}$ são as constantes empíricas para o processo particular de ozonização (descoloração). Considerando-se que [cro] e [cro $]_{0}$ podem ser determinados experimentalmente por espectroscopia UV-Vis, aplicando a lei de Lambert-Beer à Equação 7, a cinética de descoloração pode ser investigada experimentalmente usando a seguinte relação: ${ }^{20}$

$$
\ln \frac{A}{A_{0}}=-k_{\text {obs }} t
$$

onde a razão $\mathrm{A} / \mathrm{A}_{0}$ representa a absorbância normalizada medida num comprimento de onda fixo $(530 \mathrm{~nm})$.

A Figura 5 mostra que a descoloração apresenta um perfil cinético de pseudoprimeira ordem, com duas regiões lineares, devido à variação da natureza da espécie a ser oxidada no decorrer da ozonização, ${ }^{20}$ enquanto que a Tabela 1 reúne os dados de $k_{o b s}$ em função do $\mathrm{pH}$, o qual foi mantido constante durante a ozonização.

Tabela 1. Dependência da $k_{\text {obs }}$ com o pH . [C $]_{0}=200 \mathrm{mg} \mathrm{L}^{-1}$

\begin{tabular}{lcc}
\hline & $\mathrm{pH} 4,0$ & $\mathrm{pH} 12$ \\
\hline$K_{o b s-1} /\left(\mathrm{min}^{-1}\right)$ & 0,174 & 0,154 \\
$K_{\text {obs }-2} /\left(\mathrm{min}^{-1}\right)$ & 0,020 & 0,023 \\
\hline
\end{tabular}

Uma comparação dos dados apresentados na Tabela $1\left(0,020 \mathrm{~min}^{-1}\right.$ $\leq k_{o b s} \leq 0,174 \mathrm{~min}^{-1}$ ) com o valor experimental do valor do coeficiente de transferência de massa volumétrico do ozônio $\left(k_{\mathrm{L}} \mathrm{a}=0,41 \min ^{-1}\right), \mathrm{o}$ qual foi determinado em condições experimentais idênticas às deste trabalho, ${ }^{24}$ indica que a reação química de descoloração pode ser considerada um processo lento quando comparado com o processo de transferência de massa do ozônio. De fato, de acordo com a literatura, ${ }^{43}$ a reação química de descoloração dos corantes do tipo azo, em soluções ácida e alcalina, compreende a etapa determinante de velocidade do processo de ozonização global, mesmo para o caso onde $k_{\mathrm{L}} \mathrm{a}<0,3 \mathrm{~min}^{-1}$. Portanto, podemos concluir que a reação química entre $\mathrm{O}_{3}$ e/ou $\mathrm{OH}^{\bullet}$ e os centros cromóforos governa a velocidade global do processo de descoloração através da ozonização.

De acordo com Chu et al.,43 o processo de descoloração é acompanhado por um aumento do fator de efetividade $(E)$ durante o estágio inicial da ozonização compreendendo o ataque primário do ozônio aos grupos cromóforos (grupos ligantes azo), enquanto durante o segundo estágio da ozonização o fator de efetividade diminui ligeiramente como consequência da natureza recalcitrantre da reação entre ozônio e/ou $\mathrm{OH}^{\bullet}$ e os subprodutos da degradação.

Wu e Wang ${ }^{47}$ propuseram uma relação linear empírica para o processo de descoloração o qual correlaciona, para uma dada temperatura, o parâmetro $E$ com a concentração inicial do corante $[C]$ e a velocidade de aplicação do ozônio $\left(\mathrm{V}_{\mathrm{PEO}}\right)$. Esta relação é descrita como $E=x+y[C]+z\left(v_{P E O}\right)$, onde $\mathrm{x}$, y e z são parâmetros experimentais determinados para cada sistema de corante. De acordo com estes autores, ${ }^{47} E$ aumenta com $[\mathrm{C}]$ devido à cinética química, visto que a ozonização do corante é de primeira ordem em relação a $\mathrm{O}_{3}$ e ao corante. Portanto, o valor de $E$ deveria aumentar (y $>0)$ com a concentração de ambos, o corante e o ozônio dissolvido. Contudo, mantendo-se constante $v_{P E O}$ em condições de semibatelada, a ozonização torna-se de pseudoprimeira ordem em relação ao corante, e o parâmetro $E$ aumenta linearmente devido somente a [C]. Wu e Wang ${ }^{47}$ também reportaram que aumentando o valor de $v_{P E O}$ a turbulência na interface gás/líquido também aumenta, aumentando assim a transferência de massa $(z>0)$. Os autores ainda relataram a influência de [C] e $v_{P E O}$ sobre $k_{\text {obs }}$ e encontraram que $k_{o b s}$ decai logaritmicamente com [C]. Este comportamento foi descrito pela relação $k_{o b s}=w[\mathrm{C}]^{-m}$, onde $w$ e $m$ são constantes empíricas. O estudo efetuado por esses autores revelou que a relação $\operatorname{linear} \log \left(k_{\text {obs }}\right)$ vs. $\log ([\mathrm{C}])$ é sempre verdadeira para corantes azo, independentemente da coexistência de outros compostos.

A análise dos dados apresentados na Figura 5 e Tabela 1 claramente suporta que os valores de $k_{o b s}$ dependem do $\mathrm{pH}$. Não se pode afirmar o mesmo em relação à concentração, porque este tema não foi objeto de estudo neste trabalho. Entretanto, a dependência de $k_{o b s}$ com o tempo de ozonização em ambas as soluções, ácida e básica, revela um cenário mais complexo para o processo de descoloração. Estas observações estão de acordo com a literatura, ${ }^{10,20}$ onde se reporta a dependência de $k_{o b s}$ com a composição, $[\mathrm{C}]_{0}$ e pH, podendo esta apresentar mais que um valor durante o processo de ozonização.

Uma comparação dos valores de $k_{o b s}$ em função do $\mathrm{pH}$, mostrados na Tabela 1, suporta que ambos os caminhos, oxidação direta e indireta, têm papel similar durante a descoloração. Este comportamento pode ser compreendido considerando que ambos $\mathrm{O}_{3} \mathrm{e} \mathrm{OH}^{\bullet}$ apresentam uma forte natureza eletrofílica, os quais facilitam consideravelmente o ataque aos centros cromóforos.

À luz da discussão apresentada por Franco et al. ${ }^{20} \mathrm{e}$ considerando que $v_{\mathrm{PEO}},\left[\mathrm{OH}^{-}\right]$e $[\mathrm{cro}]_{0}$ são constantes para cada caso, pode-se propor que as mudanças nos valores de $k_{o b s}$ em função do tempo de ozonização, observado em meio ácido e básico, podem ser atribuídas às modificações ocorridas nas cinéticas intrínsecas entre o oxidante $\left(\mathrm{O}_{3}\right.$ e/ou $\left.\mathrm{OH}^{\bullet}\right)$ e os centros cromóforos.

A cinética de descoloração pode ser dividida em três estágios ${ }^{20}$ : ataque primário - o processo de descoloração é governado pela reação 
química envolvendo o oxidante $\left(\mathrm{O}_{3}\right.$ e/ou $\left.\mathrm{OH}^{\bullet}\right)$ e os centros cromóforos mais reativos da molécula inicial (parental); ataque secundário (transiente) - a velocidade de remoção de cor é influenciada pelas mudanças na natureza intrínseca do processo de oxidação como consequência da competição entre os novos centros cromóforos presentes nos subprodutos coloridos persistentes transitórios, os quais são formados após o ataque primário e, ataque terciário (último estágio da descoloração) - remoção de cor devido à oxidação do centro cromóforo remanescente presente nos subprodutos coloridos persistentes transitórios.

Considerando a discussão acima, a mudança no $k_{o b s} \operatorname{com} o$ tempo de ozonização pode ser atribuída às modificações na razão [corante]/[subprodutos], ocasionando uma considerável modificação na cinética intrínseca entre o oxidante $\left(\mathrm{O}_{3}\right.$ e/ou $\left.\mathrm{OH}^{*}\right)$ e os centros cromóforos. ${ }^{20}$ Uma comparação entre o $k_{o b s-1}$ e $k_{o b s-2}$ indica que o estágio secundário da oxidação corresponde à etapa lenta da descoloração. Estes resultados também indicam que a reação química entre o oxidante $\left(\mathrm{O}_{3}\right.$ e/ou $\left.\mathrm{OH}^{\circ}\right)$ e a molécula parental (inicial) é a etapa rápida, diminuindo consideravelmente os centros cromóforos presentes na molécula parental quando comparados aos centros cromóforos presentes nos subprodutos. Além disso, há um aumento considerável na natureza recalcitrante dos subprodutos quando comparado aos centros cromóforos presentes na molécula do vermelho GRLX-220. Do ponto de vista teórico, este comportamento complexo apresentado pelo $k_{o b s}$ reflete a importante influência das propriedades intrínsecas dos centros cromóforos (densidade eletrônica) na cinética de descoloração.

\section{Influência do pH sobre a degradação do Vermelho GRLX-220}

A velocidade de degradação do Vermelho GRLX-220 usando ozônio gerado eletroquimicamente foi avaliada medindo-se a redução de COT. Medidas de DQO foram efetuadas de modo a fornecer informações sobre a susceptibilidade da matéria orgânica à oxidação química. ${ }^{29}$ A Figura 6 exibe a influência do $\mathrm{pH}$ sobre a remoção do COT e DQO.

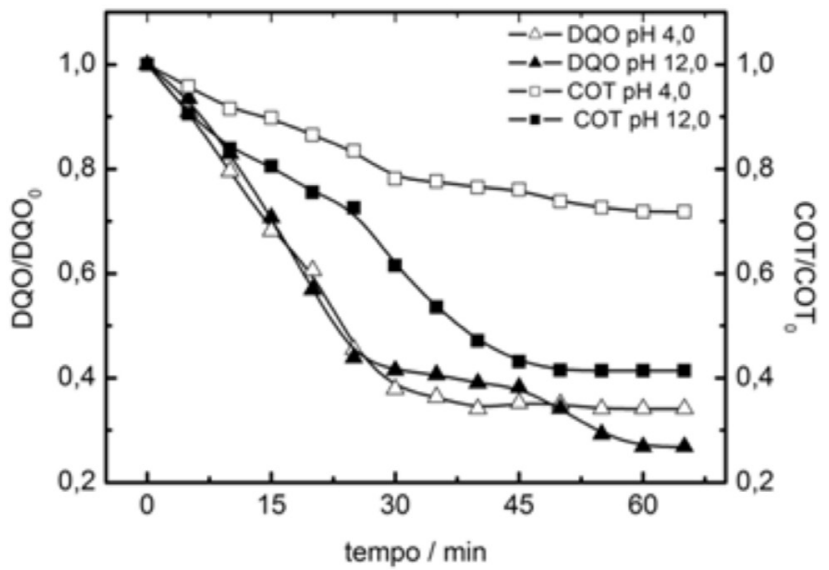

Figura 6. Influência do pH da solução e tempo de ozonização sobre a remoção de DQO-COT. $[C]_{o}=200 \mathrm{mg} \mathrm{dm}^{-3} ; v_{P E O}=0,48 \mathrm{~g} \mathrm{~h}^{-1}$

Observa-se que há uma diminuição considerável nos valores de DQO e COT em relação ao início do processo de ozonização, principalmente nos 30 min iniciais. Mostra também que a velocidade de remoção de DQO é pouco afetada pelo $\mathrm{pH}$, enquanto que a velocidade de remoção de COT é superior em meio alcalino. $\mathrm{O}$ fato da velocidade de remoção do COT ser mais pronunciada quando a ozonização é efetuada em meio alcalino é consequência do potencial de oxidação superior apresentado pelo radical hidroxila $\left(E^{\circ}=2,80 \mathrm{~V}\right.$ vs. ERH) quando comparado ao do ozônio $\left(E^{\mathrm{o}}=2,07 \mathrm{~V}\right.$ vs. ERH $){ }^{33}$

Uma análise criteriosa da Figura 6 revela também que a redução de COT em meio ácido para tempos de ozonização superiores a 30 min não é muito pronunciada, indicando que o caminho da oxidação direta via $\mathrm{O}_{3}$ não constitui um processo eficiente para posterior oxidação dos subprodutos da ozonização. Pelo contrário, em condições alcalinas, ocorre uma redução considerável de COT durante todo o intervalo de ozonização, sendo esta redução ainda superior após 30 min de ozonização, onde já houve quase total remoção de cor e predomínio da existência dos subprodutos da reação de ozonização. Esta observação revela que a natureza não seletiva do processo oxidativo indireto pelos radicais $\mathrm{OH}^{\bullet}$ resulta numa degradação contínua dos subprodutos da ozonização.

A Tabela 2 apresenta valores da susceptibilidade de oxidação da matéria orgânica solúvel, expressos pelo parâmetro $\gamma$ (= DQO/ COT), obtidos no transcorrer dos experimentos de ozonização, em função dos pH's investigados. ${ }^{29}$ Pode-se observar que inicialmente $\gamma$ diminui com o aumento do tempo do experimento, permanecendo praticamente constante após 30 min de ozonização. A diminuição de $\gamma$ indica que a ozonização conduz a um aumento da susceptibilidade de oxidação da matéria orgânica solúvel e que, de acordo com os resultados exibidos na Figura 6, a redução de DQO é mais acentuada que a do COT nos primeiros $30 \mathrm{~min}$ de experimento. Em tempos superiores de ozonização, as taxas da remoção de DQO e COT caminham paralelamente. Este tipo de comportamento evidencia que a susceptibilidade da matéria orgânica à oxidação química não é mais alterada pela ozonização nas condições experimentais utilizadas, ou seja, para $t>30 \mathrm{~min}$.

Tabela 2. Valores de $\gamma$ (= DQO/COT) em função do tempo de ozonização e do $\mathrm{pH}$

\begin{tabular}{ccc}
\hline tempo/min & $\mathrm{pH} \mathrm{4,0}$ & $\mathrm{pH} \mathrm{12}$ \\
\hline 0 & 2,57 & 2,38 \\
10 & 2,26 & 2,25 \\
20 & 1,80 & 1,75 \\
30 & 1,28 & 1,48 \\
40 & 1,22 & 1,50 \\
50 & 1,25 & 1,51 \\
60 & 1,26 & 1,52 \\
\hline
\end{tabular}

Neste contexto, o parâmetro $\gamma$ serve como um indicador da extensão do tratamento químico visando sua conjunção com o processo biológico convencional de baixo custo. ${ }^{20}$ Conforme discutido por Da Silva e Jardim,,$^{23}$ o uso de processos de tratamentos integrados visa aumentar a eficiência do processo biológico da forma menos onerosa possível, fazendo-se uso de processos químicos não convencionais apenas no tratamento inicial do efluente, ou seja, quando este exibe elevados níveis de recalcitrância.

\section{Toxicidade do Vermelho GRLX-220 e dos subprodutos da ozonização}

Os testes de toxicidade devem ser considerados como uma análise indispensável no monitoramento dos efeitos causados pelos efluentes têxteis no meio ambiente aquático, a fim de se avaliar a capacidade do agente tóxico produzir efeitos deletérios em organismos vivos. De acordo com Silva, ${ }^{48}$ as necessidades de se obter informações não reveladas pela simples caracterização físico-química, da complexidade e variabilidade apresentada pelos compostos orgânicos e inorgânicos, 
têm estimulado a realização de testes de toxicidade, nos quais os efeitos são mensurados através da reposta dos organismos vivos.

Neste contexto, degradações realizadas com o efluente sintético foram acompanhadas com testes de toxicidade efetuados com o microcrustáceo Artemia salina. Os resultados são apresentados na Figura 7, a qual contém os valores médios da porcentagem de mortalidade das Artemias salinas corrigidas pela fórmula de Abbot. ${ }^{39}$

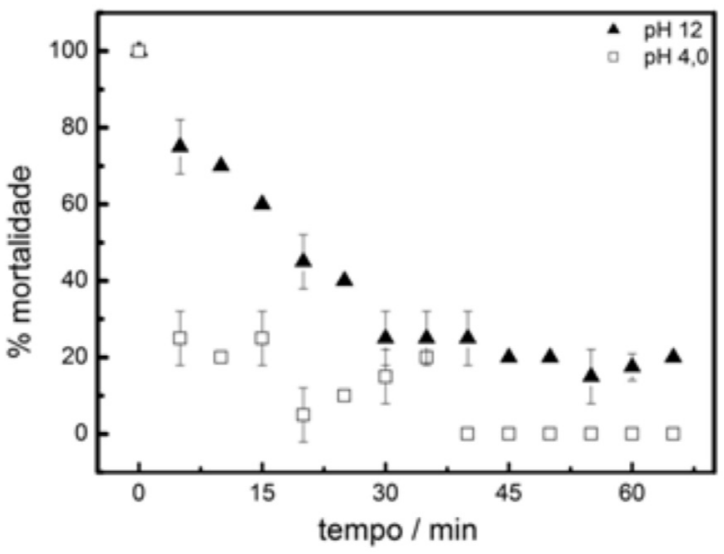

Figura 7. Porcentagem de mortalidade de Artemia salina em soluções do corante Vermelho GRLX- 220 em função do tempo de degradação com ozônio

Independentemente do meio, os resultados mostram que ocorre uma redução significativa da taxa de mortalidade das Artemias salinas, indicando que há uma redução significativa da toxicidade dos produtos da ozonização. Observa-se também que a mortalidade é maior em meio básico e a possível justificativa para o comportamento em relação ao $\mathrm{pH}$ pode estar na natureza dos subprodutos da degradação, que devem ser diferentes de acordo com cada $\mathrm{pH}$ investigado.

Os resultados mostram também que, em relação às soluções iniciais do composto parental, a redução de mortalidade chega a $100 \%$ em meio ácido e $80 \%$ em meio básico, demonstrando que os subprodutos da degradação são bem menos tóxicos que o composto parental.

\section{CONCLUSÕES}

Os resultados dos estudos da descoloração e degradação do efluente sintético contendo o corante têxtil Vermelho GRLX-220 suportam que a tecnologia da ozonização pode se constituir numa alternativa promissora para remediar problemas ambientais relacionados ao tratamento de efluentes têxteis.

O estudo cinético da descoloração e as análises da remoção de DQO e COT em função do tempo de ozonização, efetuadas em soluções ácidas e alcalinas, revelam que a ozonização se constitui numa tecnologia eficiente para ambos, remoção de cor e de matéria orgânica. Uma total descoloração foi obtida rapidamente em ambos pH's, revelando assim que ambos, mecanismo oxidativo direto $\left(\mathrm{O}_{3}\right)$ e indireto $\left(\mathrm{OH}^{\bullet}\right)$, são eficientes para a remoção de cor para este tipo de corante. A cinética de descoloração segue um modelo de pseudoprimeira ordem, sendo influenciada pelo $\mathrm{pH}$ e também pelo tempo de ozonização.

Um grau considerável de mineralização ( 60\%) foi obtido em meio básico após 30 min de ozonização utilizando uma baixa velocidade de aplicação de ozônio $\left(\sim 0,50 \mathrm{~g} \mathrm{~h}^{-1}\right)$. Além disso, também se encontrou que a ozonização, tanto em meio ácido como alcalino, promove um considerável aumento na viabilidade de oxidação da matéria orgânica solúvel.

Finalmente, os testes de toxicidade revelaram que os subprodutos da degradação através da aplicação de ozônio são menos tóxicos que o produto inicial, demonstrando a potencialidade do sistema empregado neste estudo na geração de compostos recalcitrantes menos poluentes que os compostos parentais.

\section{AGRADECIMENTOS}

L. A. de Faria agradece ao CNPq pelo apoio financeiro (Edital Universal 2006 processo 479373/06-0) e pela concessão da Bolsa de Produtividade em Pesquisa. L. M. da Silva agradece à FAPEMIG (Processo CEX - APQ-00705-09) e ao CNPq pela Bolsa de Produtividade em Pesquisa concedida em 2009.

\section{REFERÊNCIAS}

1. http://www.abiquim.org.br/corantes/cor_industria.asp, acessada em Maio 2011.

2. Szpyrkowicz, L.; Juzzolino, C.; Kaul, S. N.; Water Res. 2001, 35, 2129.

3. Meriç, S.; Kaptan, D.; Ölmez, T.; Chemosphere 2004, 54, 435.

4. Churchley, J. H.; Ozone Sci. Eng. 1998, 20, 111.

5. Shu, H. Y.; Huang, C. R.; Chemosphere 1995, 31, 3813.

6. Arslan, I.; Balcioglu, I. A.; Tuhkanen, T.; Bahnemann, D. W.; J. Environ. Eng. 2000, 126, 903.

7. Torrades, F.; Montaño, J. G.; Hortal, J. A. G.; Domènech, X.; Peral, J.; Solar Energy 2004, 77, 573.

8. Meriç, S.; Selçuk, H.; Belgiorno, V.; Water Res. 2005, 39, 1147.

9. Konsowa, A. H.; Desalination 2003, 158, 233.

10. Hsu, Y. C.; Chen, J. T.; Yang, H. C.; Chen, J. H.; AIChE J. 2001, 47,169.

11. Hao, O. J.; Kim, H.; Chiang, P. C.; Crit. Rev. Environ. Sci. Technol. 2000, 30, 449 .

12. Zollinger, H.; Color Chemistry, $2^{\text {nd }}$ ed., V.C.H. Publishers: New York, 1991.

13. Weber, E. J.; Stickney, V. C.; Water Res. 1993, 27, 63.

14. El-Sharkawy, E. A.; Soliman, A. Y.; Al-Amer, K. M.; J.Colloid Interface Sci. 2007, 310, 498.

15. Lin, S. H.; Chen, M. L.; Water Res. 1997, 31, 868.

16. Masten, S. J. S.; Davies, H. R.; Environ. Sci. Technol. 1994, 28, 181.

17. Guaratini, C. C. I.; Zanoni, M. V. B.; Quim. Nova 2000, 23, 71.

18. Da Silva, L. M.; Jardim, W. F.; Quim. Nova 2006, 29, 310.

19. Szpyrkowicz, L.; Juzzolino, C.; Kaul, S. N.; Water Res. 2001, 35, 2129.

20. Franco, D. V.; Boodts, J. F. C.; Jardim, W. F.; Da Silva, L. M.; Clean 2008, 36, 34 .

21. Chu, W.; Ma, C-W.; Water Res. 2000, 34, 3153.

22. Gogate, P.; Pandit, A. B.; Adv. Environ. Res. 2004, 8, 553.

23. Da Silva, L. M.; Franco, D. V.; Forti, J. C.; Jardim, W. F.; Boodts, J. F. C.; J. Appl. Electrochem. 2006, 36, 523.

24. Santana, M. H. P.; Da Silva, L. M.; Freitas, A. C.; Boodts, J. F. C.; Fernandes, K. C.; De Faria, L. A.; J. Hazard. Mater. 2009, 164, 10.

25. Eckenfelder, W. W. Jr.; Industrial Water Pollution Control, $2^{\text {nd }}$ ed, McGraw-Hill: New York, 1989.

26. Diaper, E. W. J. Em Ozone in Water and Wastewater Treatment; Evans, F. L., ed.; Ann Arbor Science Publishers: Michigan, 1972.

27. Da Silva, L. M.; Santana, M. H. P.; Boodts, J. F. C.; Quim. Nova 2003, 26,880 .

28. Da Silva, L. M.; Jardim, W. F.; Quim. Nova 2006, 29, 310.

29. Marco, A.; Esplugas, S.; Saum, G.; Water Sci. Technol. 1997, 35, 321.

30. Da Silva, L. M.; De Faria, L. A.; Boodts, J. F. C.; Pure Appl. Chem. 2001, 73, 1871.

31. Sheng, H. L.; Chi, M. L.; Water Res. 1993, 27, 1743.

32. Tzitzi, M.; Vayenas, D. V.; Lyberatos, G.; Water Sci. Technol. 1994, 29, 151.

33. Hoigné, J. Em Mechanisms, Rates and Selectivities of Oxidation of Organic Compounds Initiated by Ozonation in Water; Rice, R. G.; Netzer, A., eds.; Ann Arbor Science Publishers: Michigan, 1982, p. 341. 
34. Kunz; A.; Mansilla, H.; Furan, N.; Environ. Technol. London. 2002, 23, 911.

35. Foller, P. C.; Kelsall, G. H.; J. Appl. Electrochem. 1993, 23, 996.

36. Foller, P. C.; Ozone: Sci. Eng. 1984, 6, 29.

37. American Public Health Association; Standard Methods for the Examination of Water and Wastewater, $17^{\text {th }}$ ed., APHA: Washington, D.C., 1989.

38. Meyer, B. N.; Ferrigini, N. R.; Putnan, J. E.; Jacobsen, L. B.; Nichols, D. E.; Mclaughlin, J. L.; Planta Med. 1982, 45, 31.

39. Abbott, W. S.; J. Economic Entomology 1925, 18, 265.

40. López-López, A.; Pic, J. S.; Debellefontaine, H.; Chemosphere 2007, $66,2120$.

41. Chen, L. C.; Water Res. 2000, 34, 974.
42. Langlais, B.; Reckhow, D. A.; Brink, D. R.; Ozone in Water Treatment: Application and Engineering, CRC Press LLC: Boca Raton, 1991.

43. Chu, L. B.; Xing, X. H.; Yu, A. F.; Zhou, Y. N.; Sun, X. L.; Jurcik, K.; Chemosphere 2007, 68, 1854.

44. Peng, R. Y.; Fan, H. J.; Dyes Pigm. 2005, 67, 153.

45. Whitlow, J. E.; Roth, J. A.; Environ. Progress 1988, 7, 52.

46. Hoigné, J.; The Chemistry of Ozone in Process Technologies for Water Treatment, Plenum-Press: New York, 1988.

47. Wu, J.; Wang, T.; Water Res. 2001, 35, 1093.

48. Silva, A. C.; Dissertação de Mestrado, Universidade Federal do Rio de Janeiro, Brasil, 2002. 